\title{
AS IDENTIDADES DE GÊNERO NO ESPAÇO CÊNICO LA PIEL QUE HABITO DE PEDRO ALMODÓVAR
}

\section{The gender identities in the scenic scenery of pedro almodóvar's the skin i live in}

\author{
Guaraci da Silva Lopes Martins ${ }^{13}$ \\ Tânia Rosa F. Cascaes ${ }^{14}$
}

\section{Resumo:}

Instigadas pelo interesse em aprofundar os conhecimentos sobre as relações de poder que permeiam as configurações de gênero as autoras elaboraram o presente texto, recorrendo à linguagem cinematográfica compreendida pelas mesmas como um terreno fértil para a problematização sobre o assunto. Diante desta proposta o texto apresentado se concentra na obra $A$ Pele Que Habito de Pedro Almodóvar, sobretudo pela obra específica tratar sobre configurações de gênero que desestabilizam a regulação binária da sexualidade pautada nas distinções anatômicas dos corpos. Cabe destacar que o referido filme é um convite à reflexão sobre as contribuições das novas tecnologias no processo de novas percepções sobre sujeitos masculinos ou femininos. Neste sentido, este trabalho busca contribuir para a discussão sobre as condições sociais que proporcionam o deslizamento e/ou ressignificação das identidades que, longe de serem estáveis são passíveis de transformação.

13 Doutora em Artes Cênicas pela UFBA; Mestre em Educação pela Universidade Tuiuti do Paraná; docente da Universidade Estadual do Paraná-UNESPAR/FAP. Líder do Grupo de Pesquisa Arte, Educação e Formação Continuada; Membro do Grupo de Estudos e Pesquisas sobre Relações de Gênero e Tecnologia/GeTec e do GT Pedagogia do Teatro \& Teatro e Educação da ABRACE. Curitiba/Brasil.

14 Mestre em Tecnologia e Trabalho pela UTFPR com a Dissertação "O Instituto de Tecnologia para o Desenvolvimento - LACTEC - na Gênese do Processo Tecnológico Paranaense: uma contribuição ao Estudo da História da Técnica e da Tecnologia". Socióloga; Especialista em Docência Superior. Pesquisadora do Grupo de Estudos e Pesquisas em Relações de Gênero e Tecnologia - GETEC-CNPq do PPGTE - Programa de Pós-Graduação em Tecnologia da Universidade Tecnológica Federal do Paraná - UTFPR. Curitiba/Brasil. 
Palavras-chave: identidades, gênero, sexualidade, cinema.

\section{Abstract:}

Instigated by the interest in furthering knowledge about power relations that permeate the gender settings the authors have developed this text, which resorting to cinematic language understood by them as a breeding ground for questioning on the subject. Given this proposed text, the presented work focuses on The Skin That Live In by Pedro Almodóvar, particularly the work on treating specific settings that destabilize gender binary regulation of sexuality guided by anatomical distinctions bodies. It is worth noting that this film is an invitation to reflect on the contributions of new technologies in the process of new perceptions of male and female subjects. In this regard, this paper seeks to contribute to the discussion about the social conditions that give the sliding and / or redefinition of identities that, far from being stable are amenable to transformation.

Keywords: identity, gender, sexuality, cinema.

O presente artigo tem como enfoque a construção das identidades, alvo de discursos geradores de estereótipos sobre a masculinidade e a feminilidade. Para a discussão sobre o assunto recorreu-se à obra cinematográfica A Pele que Habito de Pedro Almodóvar, diretor de grande expressão no cinema pelas variadas obras de amplo sucesso sob a sua direção. Todas elas voltadas para as distintas possibilidades do sujeito viver e construir as próprias subjetividades e desta forma, contribuindo para evidenciar a instabilidade e a fluidez das identidades de gênero e sexuais.

Nesta etapa do texto considera-se importante uma breve explanação sobre A Pele Que Habito, compreendida como sendo uma obra de suma relevância para a reflexão sobre o amplo leque de conceitos marcados pela lógica que aponta para a naturalização dos gêneros. Importa destacar que o ator Antonio Banderas dá vida ao Dr. Robert Ledgard, um respeitável cirurgião plástico de transplantes de pele que passou a se dedicar no processo de criação de uma pele resistente e com a qual a esposa Gal teria sobrevivido. Ela cometeu suicídio após sofrer graves queimaduras em um acidente de carro.

Inicialmente o filme analisado leva para a tela a estranha relação entre 
o médico e Vera. Esta personagem é objeto de trabalho de Robert, obstinado em seu em processo de construção de uma pele a ser implantada em Vera que aparenta ser sobrevivente de alguma tragédia. Gradativamente a obra revela que esta mulher se mantém como refém na mansão deste cirurgião que, após o estupro de sua filha Robert reconstrói o corpo de Vicente transformando-o em Vera e tendo como modelo a imagem perdida de Gal. Para tal objetivo, o cirurgião conta apenas com a sua governanta para atingir o desejo de vingança.

Numa determinada cena, a filha de Robert se encontra com Vicente em uma festa quando demonstra uma forte atração pelo mesmo. No momento em que ambos se encontram a sós em uma parte isolada da residência, especialmente no jardim, ambos iniciam preliminares amorosas, as quais são interrompidas pela jovem numa inesperada demonstração de repulsa que é desconsiderada por Vicente movido pelo seu intento de consumar o ato sexual. É oportuno assinalar que ainda hoje convive-se em uma sociedade caracterizada por modelos opressores que se constituem na interação social pautada por binarismos hierarquizados marcados pela dominação patriarcal. Neste contexto, especialmente a mulher sofre variadas formas de discriminação em uma evidente relação de subordinação e controle sobre o diferente.

Ainda que o movimento feminista tenha contribuído sobremaneira para ampliar o espaço da mulher nas esferas públicas e privadas, ainda hoje este gênero específico enfrenta amplos desafios para o seu efetivo empoderamento. Destaca-se que a violência se faz presente na vida da mulher de variadas faixas etárias e classes sociais, fenômeno este perversamente cometido no contexto sociocultural. Segundo Daniela Auad (2003), há um conjunto de ideias que acabam causando a violência. Dentre outras, a mentalidade de que os homens devem controlar a vida das mulheres, evidenciando a evidência do Patriarcalismo.

Por ouro lado, concordando com Foucault (2004) onde há poder também há resistência ratificando que o sujeito nunca foi liberto e jamais se libertará, pois sempre haverá poder. Para este autor, é possível, modificar a dominação em condições determinadas e segundo uma estratégia precisa. 
Neste sentido, é possível a afirmação de que as mulheres podem oferecer resistência aos processos de exploração-dominação que sobre elas recaem, muitas vezes culminando em êxitos.

Salienta-se as contribuições do movimento feminista na sua luta pela desestabilização de discursos biológicos e naturalizados permeados pela subordinação para justificar as condições sociais das mulheres No entendimento de Tomaz Tadeu da Silva (2005, p. 93), "as análises feministas mais recentes enfatizam, de forma crescente que o mundo social está feito de acordo com os interesses e as formas masculinas de pensamento e conhecimento". Neste contexto, o movimento feminista que teve início na década de 1960 permanece como uma força social importante para a subversão de conceitos que reforçam estereótipos que relegam às mulheres papéis socialmente considerados inferiores.

Assim como o movimento feminista, outros movimentos surgem na luta para a desestabilização de situações contra sujeitos considerados "desviantes" da norma heteronormativa. De fato, desde os anos sessenta, a problematização sobre o processo construído das identidades se amplia, especialmente instigado pelo movimento feminista, e demais identidades sociais que buscam a sua visibilidade, tais como, os movimentos gays, lésbicos, queers, bissexuais, transexuais e travestis que gradativamente, emergem publicamente e evidenciam a fluidez das identidades sexuais.

O efeito e o impacto das experiências de sujeitos que de alguma forma rompem com as rígidas fronteiras estabelecidas aos gêneros culminam em ações fortemente políticas. Este deslocamento interfere não apenas as suas próprias vidas, mas repercute na vida de seus contemporâneos, pois ao se construírem no espaço da resistência às normas regulatórias, "afetam, assim, não só seus próprios destinos, mas certezas, cânones e convenções culturais" (LOURO, 2008, p. 24-25). Estes sujeitos evidenciam a pluralidade de interpretações e de construções de subjetividade com significados múltiplos. Ou seja, contrariam discursos excludentes geradores de estereótipos norteados por ideias cristalizadas sobre as identidades monolíticas e coerentes com tendência à definição de comportamento e de papéis sociais.

Antes de nascer, o corpo já está inscrito em um campo discursivo determinado na e pela configuração ideológica, estruturada por uma rede de 
pressuposições sobre comportamentos, gostos e subjetividades que estruturam as performances de gênero. Em Berenice Bento (2006) lemos que o corpo é um texto socialmente construído, um arquivo da história do processo de produção-reprodução sexual que ganha inteligibilidade por intermédio da heterossexualidade condicionada e circunscrita pelas convenções históricas.

Sabe-se que a partir do nascimento do sujeito investe-se em discursos direcionados para a preparação de corpos, cuja subjetividade é construída sobre proibições e afirmações. Neste contexto, a transgressão de uma regra se caracteriza como um desvio e, concordando com Howard Becker (2009), este ato significa a infração de uma determinada regra geralmente aceita pelos grupos sociais que criam o desvio ao elaborarem normas cuja infração constitui-se em irregularidade. Assim sendo, o desvio deixa de ser uma qualidade do ato cometido por alguém e cujas penalidades são aplicadas por outros. Para exemplificar, ser transgênero só é possível na interação entre aquele que comete a infração às regras do sistema sexo-gênero e aquele que a percebe e nomeia como desvio. Em geral, este mesmo sujeito encontra o seu espaço de pertencimento em guetos definidos pela sua orientação sexual, pois a matriz cultural por intermédio da qual a identidade de gênero se torna inteligível requer que certos tipos de 'identidade' permaneçam à margem.

As formas idealizadas dos gêneros geram hierarquias e exclusão, na medida em que os regimes de verdades estipulam que certos tipos de expressões relacionadas com o gênero são falsos ou carentes de originalidade, enquanto outros são verdadeiros e originais, condenando a uma morte em vida, exilando em si mesmo os sujeitos que não se ajustam às idealizações. (BENTO, 2006, p.94)

O transtorno ou desvio é evidenciando na interação entre o saber médico que busca o diagnóstico e as performances de gênero que o evidencia, cabendo enfatizar que o diagnóstico de transexualidade é realizado, a partir de uma exaustiva avaliação, que inclui um histórico completo do caso, testes psicológicos e sessões de terapia. Em geral, a cirurgia de readequação de sexo implica numa mudança radical da vida de sujeitos, cabendo destacar a rígida divisão de papéis e comportamentos sociais estabelecida aos 
homens e às mulheres. Erving Goffman (1988) argumenta que o estigma é produzido na dissimetria entre as expectativas sociais e os atributos biológicos: a identidade social virtual (expectativas) e a identidade social real (atributos).

Na obra cinematográfica Vincente passou a ser o elemento "desviante" após a reconstrução do seu corpo, lembrando que a cirurgia de transexualização pela qual ele passou ocorreu sem a própria autorização, intervenção esta que funcionou para o cirurgião Robert como o castigo merecido. Ao se ao se opor a outra categoria para além do binarismo homem/mulher, ao sujeito "desviante" impõe-se uma definição relacionada à construção da sua subjetividade para ocupar o espaço social. Essa película nos reporta aos filmes de terror, ainda que em nenhum momento o espectador seja surpreendido com cenas explícitas de violência, ao contrário o envolve numa fronteira de tensão pela esfera psicológica e emocional. Nesta etapa da pesquisa, considera-se importante um diálogo com a sinopse do filme segundo a qual,

\footnotetext{
o terror tem muitas esferas. Ao se falar em filme de terror, muitos esperam sangue, mutilação, psicopatas mascarados, zumbis, aliens, qualquer coisa menos um terror psicológico. Aquele pânico que sobe no corpo sem ver ao menos uma gota de sangue na tela. É disso que se trata A pele que habito. Cirurgião obcecado em criar uma pele quase invulnerável, mantém jovem presa em um cômodo da sua casa para que ela possa ser cobaia de seu experimento" (sinopse do filme A pele que habito, 2011, de Pedro Almodóvar).
}

Cabe salientar que o diretor conduz as cenas por meio de um mosaico que gradativamente expõe a história marcada por ideias obsessivas. Essa obra que evidencia a presença ou ausência de um órgão como fator determinante no comportamento, papel social e desejo - sempre pelo sexo oposto - do sujeito sexuado. Para as autoras Sophia Padilha Menezes e Maria da Conceição Bezerra dos Santos (2012), no filme, o médico age de acordo com a instrução do saber médico centrado no modo biológico de compreender as subjetividades dos corpos norteada pela lógica binária e coerente entre gênero e sexo. Neste sentido, para este cirurgião, os corpos-homens possuem pênis e sem este órgão o corpo deve necessariamente ser mulher e seguir comportamentos, modos e as regras rigidamente estabelecidas 
para o sexo feminino.

O filme nos mostra um contexto sociocultural que parte de uma noção de corpo como alvo passivo sobre o qual se inscreve um conjunto de significados culturais, reforçando a ideia de uma essência naturalmente masculina ou feminina, inscrita na subjetividade. Atualmente, essa separação é questionada em algumas perspectivas teóricas, a exemplo dos estudos de Butler (2003), segundo a qual "ser" um sexo ou um gênero é fundamentalmente impossível. O gênero é o processo por meio do qual se constrói a coerência do sexo e pressupõe uma prática e um desejo heterossexual, o que implicaria numa revisão epistemológica de discursos heteronormativos.

Esta mesma obra anuncia com transparência a possibilidade de fabricação de corpos na era da tecnologia que contribui para a subversão de conceitos norteados pela fixidez das identidades. Por outro lado, ela nos convida à reflexão sobre a construção identitária que ocorre de uma forma gradual e temporal, argumentação esta que pode ser reforçada, especialmente pela experiência vivenciada pelo personagem Vicente. Para melhor compreensão, movido por impulsos obsessivos este personagem investe na própria feminilidade para seduzir Robert que é morto tragicamente pela manipulação de um corpo que passou a ser controlado e monitorado.

Gradativamente Vicente assumiu o corpo feminino em contraposição ao desejo imposto pela coerência entre corpo, gênero, sexualidade e desejo, tal como impõe a heteronormatividade compulsória, considerada a priori como inquestionável. Esse personagem foi penalizado com a redefinição de um corpo que não corresponde à sua própria orientação de gênero e sexual e nos convida à reflexão sobre os inúmeros sujeitos que desde a sua fase infantil se percebe no espaço preenchido por matrizes subversivas do gênero.

Para Sophia Padilha Menezes e Maria da Conceição Bezerra dos Santos (2012) a película aqui analisada, apregoa o controle estatal como um aparelho articulador de instituições de saber-poder, tais como escolas, exércitos, hospitais, família, dentre outras, especialistas e o próprio indivíduo. Vale ressaltar que, a escola produz e reproduz discursos universalizantes e definidores de corpos, os quais tendem a seguir as expectativas sociais idealizadas para os homens e para as mulheres. 
Por outro lado, se a instituição escolar reflete conceitos e valores tradicionalmente compreendidos como inquestionáveis, a escola é também um espaço propício para a reflexão e a negociação entre pessoas. A escola e o currículo são espaços ideais para oferecer condições necessárias para que os estudantes desenvolvam o exercício das "habilidades democráticas da discussão e da participação, de questionamento dos pressupostos do senso comum da vida social". (SILVA, 2005a, p.55) A diversidade se faz presente neste ambiente, no qual convivem pessoas com histórias de vida diferentes, incluindo-se todo o conjunto estrutural - biológico, social e cultural - que o constitui enquanto sujeito. Ressalta-se que é na pluralidade que as distintas visões da realidade se fazem perceptíveis.

Cultura diz respeito à humanidade como um todo e ao mesmo tempo a cada um dos povos nações, sociedades e grupos humanos. [...] Cada realidade cultural tem sua lógica interna, qual devemos procurar conhecer para que façam sentido as suas práticas, costume concepções e as transformações pelas quais estas passam. [...] Entendido assim, o estudo da cultura contribui no combate a preconceitos, oferecendo uma plataforma firme para respeito e dignidade nas relações humanas. (SANTOS, 1987, p. 8-9)

Por esta razão, é imprescindível o investimento em projetos pedagógicos que transcendam as formas tradicionais de a escola lidar com o único: "currículo único, normas únicas, métodos únicos, provas únicas, escola única e igual para todos". (VASCONCELLOS, 2006, p. 191) Por outro lado, a diversidade dos alunos, escolas e contextos suscita a reflexão sobre esta forma de condução do processo de ensino e aprendizagem em direção a novas perspectivas que levem em conta o fenômeno plural, heterogêneo e dinâmico que caracteriza o tecido sociocultural. Contudo, sabe-se que "ainda existe um abismo entre a cultura preconizada na escola e a cultura de referência dos alunos, principalmente se estes pertencem a grupos sociais, étnicos e culturais marginalizados" (Ibidem, p. 190)

Com efeito, de acordo com a pesquisa Juventude e Sexualidade publicada pela UNESCO no ano de 2004 o total de 39,9\% de estudantes entrevistados não gostariam de ter colegas homossexuais no espaço da sua sala de aula e 59,5\% de professores argumentaram ter um conhecimento 
insuficiente para desenvolver ações pedagógicas com enfoque na homossexualidade. Isto significa que os estudos de gênero e sexualidade devem estar incorporados na matriz curricular dos cursos de formação docente, assim como, no currículo das escolas voltadas para o ensino básico.

As desigualdades só poderão ser percebidas - e desestabilizadas e subvertidas - na medida em que estivermos atentas/ os para suas formas de produção e reprodução. Isso implica operar com base nas próprias experiências pessoais e coletivas, mas também, necessariamente, operar com apoio nas análises e construções teóricas que estão sendo realizadas. (LOURO, 1999, p.121)

Ainda segundo esta autora, a ignorância sobre a homossexualidade é seguramente uma ignorância sobre a sexualidade, o que implica em uma aceitação tácita da lógica binária e da heterossexualidade. Para especificar, ainda hoje nas escolas até mesmo as brincadeiras e os jogos são diferenciados segundo o sexo. Para Louro (1999, p. 58), "a escola delimita espaços. Servindo-se de símbolos e códigos, ela afirma o que cada um pode (ou não pode) fazer, ela separa e institui. Informa o 'lugar' dos pequenos e dos grandes, dos meninos e das meninas". O professor é um ser do e no mundo e expressa a sua interação e influências advindas de suas relações sociais. E como tal, muitas vezes leva para a sala de aula ideias essencialistas sobre os corpos marcados por genitálias específicas. Por outro lado, sobretudo em suas ações pedagógicas, este profissional corresponsável pelo processo de construção de conhecimento dos sujeitos sociais deve considerar as transformações em curso na sociedade contemporânea que abalaram e abalam uma série de certezas, refletidas nos diversos segmentos e afetando ideias cristalizadas, especialmente no que se refere às formas de pensar, de ser e de perceber as relações de gênero.

É oportuno mencionar que a linguagem cinematográfica é uma área artística de suma relevância, na medida em que vem contribuindo sobremaneira para o questionamento de discursos que permeiam as sociedades humanas, especialmente no que se refere à construção das identidades. $\mathrm{O}$ enfoque desta investigação que se concentrou na obra $A$ Pele que Habito de Pedro Almodóvar, foi de suma relevância nesta investigação movida pela proposta de problematizar as rígidas fronteiras estabelecidas às configurações de gênero consideradas pelas autoras como categorias de análise 
social.

É importante lembrar que hoje há um esforço dos movimentos sociais e das proposições de políticas públicas identitárias por uma definição que diferencie as distintas categorias. Convive-se em um contexto sociocultural marcado por binarismos hierárquicos homem-mulher; masculino-feminino; hetero-homo, baseados em discursos marcadamente androcêntricos. Salienta-se a relevância da articulação do gênero a outros aspectos da identidade social dos sujeitos, como classe, etnia, faixa etária, sexualidade, religião, dentre outras.

Pautadas no referido filme, as autoras se propuseram a contribuir para a problematização de "verdades" consideradas inquestionáveis sobre os gêneros e as sexualidades. Especialmente os recursos tecnológicos desenvolvidos nas últimas décadas, nos colocam frente à constatação de que os signos anatômicos, longe de serem fixos e estáveis podem sofrer novas configurações e interferir na forma que interpretamos o corpo masculino e o corpo feminino. Na medida em que a obra cinematográfica $A$ Pele Que Habito trata sobre processos de reformulação de conceitos relacionados à construção das identidades possibilita espaços para a problematização sobre novas possibilidades identitárias. Considera-se fundamental pensar em mulheres e homens, na sua pluralidade, lembrando que a subversão de conceitos pautados na ideia singular de masculinidade e de feminilidade culmina na inclusão das múltiplas formas de constituição dos sujeitos nas variadas esferas sociais.

\section{Referências}

AUAD, Daniela. Feminismo: que história é essa? Rio de Janeiro: DP\&A, 2003.

BECKER, Howard S. Outsiders: estudos de sociologia do desvio. 1 ed. Rio de Janeiro: Jorge Zahar, 2008.

BENTO. Berenice. A reinvenção do corpo: sexualidade e gênero na experiência transexual. Rio de Janeiro: Garamond, 2006.

BUTLER, Judith. Problemas de Gênero: feminismo e subversão da identidade. Trad. Renato Aguiar. Rio de Janeiro: Civilização Brasileira, 2003 
FOUCAULT, Michel. Ética, sexualidade, política. (org.) Manoel Barros da Motta. Trad. Elisa Monteiro, Inês Autran Dourado. Rio de Janeiro: Forense Universitária Ltda. 2004.

GOFFMAN, Erving. Estigma: notas sobre a manipulação da identidade deteriorada. 4. ed. Rio de Janeiro: LTC, 2008.

LOURO, Guacira Lopes. Gênero, sexualidade e educação: uma perspectiva pós-estruturalista. 3 ed. Petrópolis: Vozes, 1999.

LOURO, Guacira Lopes. Um corpo estranho: Ensaios sobre sexualidade e a teoria queer. 1 ed. Belo Horizonte: Autêntica, 2008.

MENEZES, Sophia Padilha e SANTOS, Maria da Conceição Bezerra dos. Estudo comparativo sobre o controle dos corpos: "A pele que habito" $\mathrm{e}$ Estado. In: XV Encontro de ciências sociais do norte e nordeste e pré-ALAS Brasil. 04 a 07 de setembro de 2012, UFPI, Teresina-PI.

SANTOS, José Luis dos. O que é cultura. 6. ed. São Paulo: Brasiliense, 1987. p. 8-9.

SILVA, Tomaz Tadeu. Documentos de Identidade: uma introdução às teorias do currículo. 9 reimp. Belo Horizonte: Autêntica, 2005b

VASCONCELLOS, Sonia Tramujas. A diversidade cultural e o ensino da arte. In: Anais do IV Fórum de Pesquisa Científica em Arte. Escola de Música e Belas Artes do Paraná, Curitiba, 2006. 